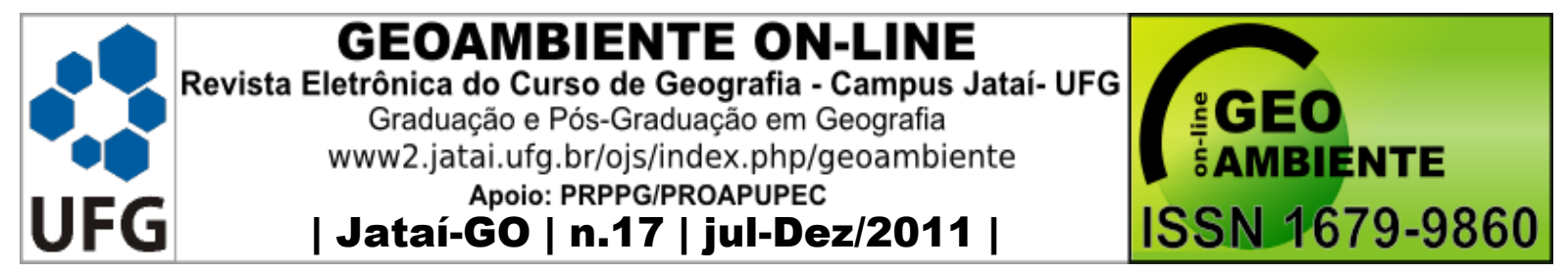

\title{
ADAPTAÇÕES METODOLÓGICAS INTERESCALARES DE ZONEAMENTOS AMBIENTAIS A BACIAS HIDROGRÁFICAS AGRÁRIAS DO SUDESTE BRASILEIRO
}

Vitor Vieira Vasconcelos ${ }^{1}$, Renato Moreira Hadad ${ }^{2}$, Paulo Pereira Martins Junior ${ }^{3}$

(1 - Universidade Federal de Ouro Preto, Assembléia Legislativa de Minas Gerais, Doutorando em Geologia, vitor.vasconcelos@almg.gov.br, 2 - Pontifícia Universidade Católica de Minas Gerais, Professor do Programa de Pós-Graduação em Geografia Tratamento da Informação Espacial, na PUC-Minas, rhadad@pucminas.br, 3 - Universidade Federal de Ouro Preto e Fundação Centro Tecnológico de Minas Gerais, Professor do Departamento de Geologia da Universidade Federal de Ouro Preto. Pesquisador do Centro Tecnológico de Minas Gerais (CETEC-MG). Doutor em Geologia, paulo.martins@ cetec.br )

\section{Resumo}

Os Zoneamentos Ambientais de frentes agrícolas brasileiras têm enfocado principalmente estudos de microescala sobre as frentes pioneiras sobre as áreas nativas do Centro-Oeste e Norte do Brasil. Contudo, vários problemas de ordenamento territorial e gestão de recursos naturais têm ocorrido em frentes agrícolas do sudeste brasileiro, apresentando particularidades sistêmicas de funcionamento. O presente artigo pretende investigar como o Zoneamento Ecológico-Econômico - ZEE -, principal instrumento de planejamento territorial brasileiro, pode adaptar sua metodologia para estudar fidedignamente as bacias hidrográficas agrárias do Sudeste do Brasil.

Palavras-chave: Zoneamento Ambiental, Bacia Hidrográfica, Frente Agrícola, Recursos Naturais, Região Sudeste, Planejamento Territorial.

\section{Abstract \\ INTER-SCALE METODOLOGY ADJUSTMENTS FOR ENVIRONMENTAL ZONING OF AGRICULTURAL BASINS AT BRAZILIAN SOUTHEAST}

The environmental zoning of Brazilian agricultural fronts have been focusing mainly on macro-scale researches of pioneer areas in Center-West and North regions. However, several problems of land use and natural resources management have been occurring in Southeastern Brazilian agricultural fronts, presenting singular systemic features. This article intends to 


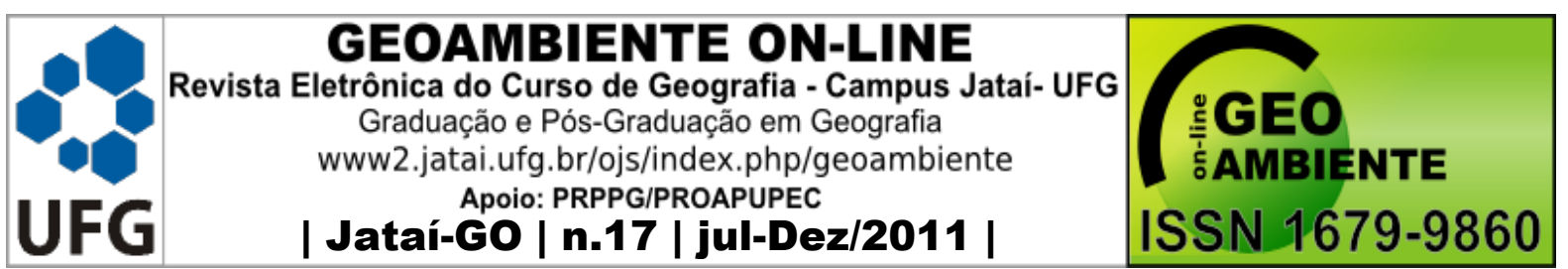

investigate how the Ecological-Economic Zoning - ZEE -, the main instrument of Brazilian territorial planning, could be adjusted to faithfully study the Southeastern Brazilian Agrarian Basins.

Keywords: Environmental Zoning, Basin, Pioneer Front, Natural Resources, Southeast Region, Territorial Planning.

\section{Resumen}

\section{ADAPTACIONES METODOLÓGICAS INTERESCALARES DE ZONIFICACIÓN AMBIENTAL EN CUENCAS HIDROGRAFICAS AGRARIAS DESDE EL SURESTE BRASILEÑO}

La zonificación ambiental de frentes agrícolas se han centrado principalmente en estudios de microescala en las frentes pioneros de áreas nativas del mydwest y norte de Brasil. Sin embargo, varios problemas de planificación regional y la gestión de los recursos naturales han ocurrido en el sureste brasileño, presentando características sistêmicas de funcionamento. Este artículo pretende investigar cómo la zonificación ecológica y económica - ZEE-principal instrumento de planificación territorial brasileño puede adaptar su metodología para estudiar fielmente las cuencas del sureste agrario de Brasil.

Palabras-clave: Zonificacíon Ambiental, Cuenca Hidrográfica, Frente Agrícola, Recursos Naturales, Region Sureste, Planificación Territorial.

\section{Introdução}

A atividade agrícola moderna, predominantemente sustentada a partir de monoculturas extensas e de elevado nível tecnológico, têm se transformado em grande usuária de recursos naturais e, consequentemente, em significante geradora de impactos ambientais. A produção de cana, soja, milho, sorgo, entre outros produtos agrícolas, acarretam em transformações drásticas da paisagem, e dentre os impactos ambientais associados às frentes agrícolas, destacam-se: compactação do solo, contaminação das águas e da biota por agrotóxicos e fertilizantes, desmatamento com a fragmentação de habitats, queimadas, redução da disponibilidade de água subterrânea e superficial pela irrigação inadequada das áreas cultivadas, redução da diversidade vegetal e animal, e perdas de solos.

Desde o ano de 1970, observa-se nas bacias hidrográficas agrícolas do Sudeste o estabelecimento progressivo de grandes sistemas de irrigação (RODRIGUEZ et al., 2007, p. 


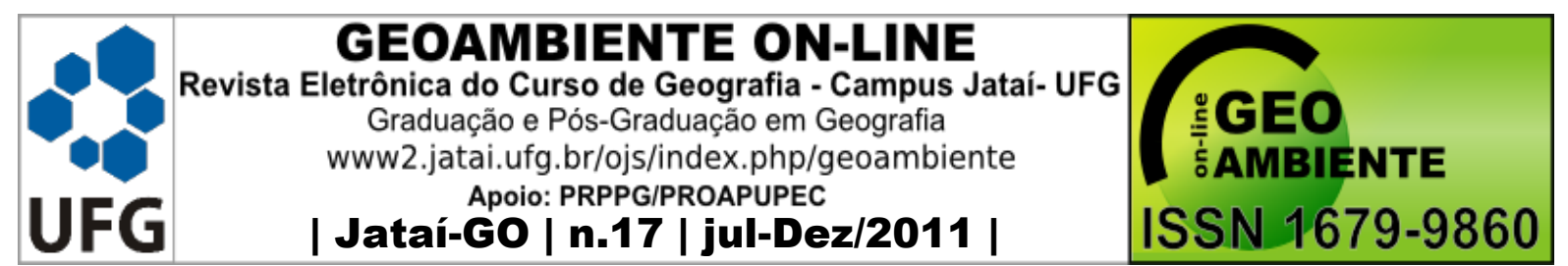

173), envolvendo diversos agricultores de forma associada. Trata-se de uma agricultura que se utiliza de tecnologia de ponta, incluindo o uso frequente de pivôs circulares de irrigação. Com a expansão dessa frente agrícola irrigada, a utilização dos recursos hídricos de recorrentemente chega a níveis critico, muito abaixo da vazão ecológica necessária para a manutenção dos ecossistemas aquáticos e terrestres associados. Em períodos de maior estiagem, são comuns inclusive conflitos entre os agricultores pelos recursos hídricos escassos (PRUSKI et al., 2007, p. 200).

Este artigo tem como objetivo pesquisar metodologias que abordem fidedignamente a interação entre os sistemas agrícolas modernos e o meio ambiente, compreendidos neste último os ecossistemas, os recursos e os serviços ambientais. Como inovação principal, sugere que seja incorporada a relação entre a agricultura moderna irrigada e os sistemas hídricos. Para tanto, é crucial incorporar a literatura sobre o estudo de frentes agrícolas, bem como sobre planejamento ambiental e zoneamentos sob o enfoque econômico-ecológico.

\section{Desenvolvimento}

\subsection{Análise Comparada de metodologias de Zoneamento Ecológico Econômico}

A discussão presente na literatura de análise comparada do Zoneamento EcológicoEconômico - ZEE - caminha por dois ângulos de visão antagônicos. Por um lado, há autores que lamentam que os diversos ZEEs tenham sido realizados com metodologias diferentes (Sérgio Braga - SDS/MMA-, em BRASIL, 2001, p. $12^{l}$ ). Baseiam esse reclame na dificuldade posterior de se integrar os estudos realizados para cada parte do país, o que prejudica um planejamento nacional, bem como análises de efeitos e processos espaciais que extrapolem os limites dos estudos.

Por outro lado, há os que diametralmente afirmam que os documentos de padronização de estudos de zoneamento, editados pelo Governo Federal, tem como defeito uma aguda rigidez metodológica (Stella Goldenstein - Secretaria do Verde e do Meio Ambiente do Município de São Paulo -, em BRASIL, 2001, p. 147). Dessa forma, só recebe repasses

1 O Zoneamento Ecológico-Econômico tem seu histórico atrelado, em grande parte, a órgãos públicos de planejamento e execução de políticas de desenvolvimento econômico e proteção do meio ambiente. Em virtude disso, grande parte da literatura sobre seu desenvolvimento estratégico e metodológico foi produzida através de encontros (chamados workshops) envolvendo representantes do meio executivo e do meio acadêmico, dos quais os debates foram publicados posteriormente. Infelizmente, as normas da ABNT não cobrem explicitamente a forma de referência e citação de debates públicos. Consideramos propício, nas referências a esses debates, citar não apenas a esfera de governo envolvida, mas também o autor da fala e seu respectivo órgão. Acreditamos que tais dados são essenciais para o leitor situar a origem e o contexto das posições proferidas. 


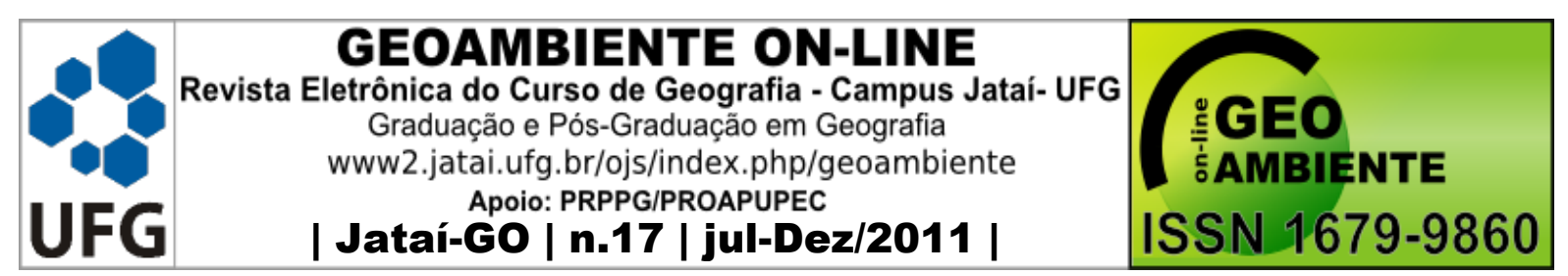

federais para realizar os estudos quem seguir as diretrizes exigidas, seja para ZEE, para Gerenciamento Costeiro ou para Zoneamento Ecológico de APAs. Todavia, cada região possui suas especificidades, e as comunidades locais também possuem interesses diferenciados quanto à ocupação do solo. Portanto, uma maior liberdade metodológica poderia levar a zoneamentos que se moldem melhor a cada situação.

A rigidez metodológica também pode constituir-se um entrave para o contínuo aperfeiçoamento das técnicas de zoneamento. Se uma equipe possui capacitação e criatividade para agregar novas análises e produtos, que serão úteis ao modelo integrador final, porque se deveria inibir essa iniciativa? Ao fim do trabalho, as inovações poderiam ser divulgadas e, com isso, agregadas ao rol de conhecimentos disponíveis. A liberdade de criação e de discussão é essencial, tanto ao desenvolvimento científico quanto ao técnico. Essa pressão pela readaptação das metodologias do ZEE foi tão enfática que resultou, em 2001, em uma reformulação das proposições iniciais, por meio do Decreto Federal no 4.297 de 2002.

O fato é que as diretrizes exigidas para o Zoneamento, no caso do ZEE, são diretrizes gerais, que permitem alguma flexibilidade, mas acabam por delimitar alguns direcionamentos. É um dilema que dificilmente se resolve, pois a estratégia de integração dos ZEE acaba dificultando a adaptação das metodologias às regiões, e vice-versa.

Essa discussão é crucial para o tema deste artigo, uma vez que, além de uma discussão comparada das metodologias, também é proposto um modelo de avaliação de fragilidade ambiental para bacias hidrográficas do Sudeste brasileiro. Adotar o modelo utilizado no ZEE de nacional traria a vantagem de possibilitar análises comparadas, bem como facilitaria a análise da bacia hidrográfica por quem já conhecer o modelo dos zoneamentos de escala ampla que já recobriram o mesmo território. Contudo, há de se questionar se, na realidade vivida na bacia objeto de estudo, não seriam mais adequadas outras formas de análise e integração dos dados. Ademais, restringir-se-ia a função de inovação do conhecimento, a qual é tarefa essencial da comunidade acadêmica.

A complexidade e abrangência de um ZEE dependem de fatores limitantes como recursos financeiros, tempo disponível, capacitação técnica e a base de informações consolidadas. Uma aproximação destes custos pode ser observada na Tabela 1. Calcula-se que, dos recursos necessários para a execução de um ZEE governamental, aproximadamente $70 \%$ dos recursos são destinados a pagamento de pessoal especializado (Marcos Estevan Del Prette, SDS/MMA, em BRASIL, 2001, p. 410). Esses limites devem ser estabelecidos por 


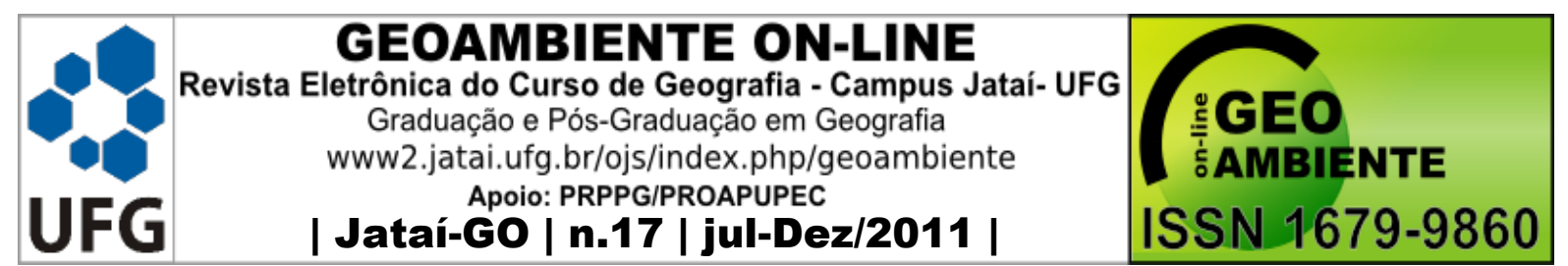

uma questão de estratégia e finalidade do poder público.

Tabela 1 - Custos de Zoneamentos Ecológico-Econômicos realizados em diversas regiões e estados do Brasil, dado por escala de trabalho.

\begin{tabular}{|c|c|c|}
\hline Escala de Trabalho & $\begin{array}{c}\text { Custo por unidade de área do terreno } \\
\left(\mathrm{US} \$ / \mathrm{km}^{2}\right)\end{array}$ & $\begin{array}{c}\text { Custo por unidade de área do mapa } \\
\left(\mathrm{US} \$ \mathrm{~cm}^{2}\right)\end{array}$ \\
\hline $1: 1.000 .000$ & 3,00 a 5,00 & 300,00 a 500,00 \\
\hline $1: 250.000$ & 10,00 a 20,00 & 62,50 a 125,00 \\
\hline $1: 100.000$ & 40,00 a 70,00 & 40,00 a 70,00 \\
\hline
\end{tabular}

Fonte: (FIDALGO, 2003, P. 140, modificado de Ross, 2001)

É normal que os pesquisadores sejam sempre desejosos de realizar zoneamentos mais e mais complexos, contribuindo assim para o desenvolvimento da ciência. Contudo, para o financiador das pesquisas, é importante dosar os recursos às prioridades e possibilidades de planejamento, ou seja, não "correr o risco de elaborar um conhecimento muito maior do que sua capacidade de aplicar esse conhecimento" (Pedro Pinchas Geiger, UFRJ, em BRASIL, 2001, p. 442), incorrendo em um custo social injustificado. Trata-se de um contraste entre o rigor acadêmico, exigido para trabalhos científicos, e o rigor de planejamento (SANTOS, 2004, p. 73).

O advento das novas tecnologias de computação, sensoriamento remoto e análise espacial, que tem se acelerado nos últimos vinte anos, permite hoje realizar trabalhos de zoneamento muito mais consistentes, detalhados e complexos (e a custos bem mais viáveis) do que quando se propôs a execução do ZEE para o Brasil. Além disso, incremento na potência e popularização da Internet permite que as informações a serem geradas por ZEE possam chegar a um número de pessoas nunca antes imaginado (Sérgio Braga, SDS/MMA, em BRASIL, 2001, p. 18).

Em todo trabalho de integração de dados geográficos para auxílio à decisão é fundamental analisar qual é a qualidade cartográfica dos insumos de dados. Tomar decisões sobre dados errados, ou em escala de detalhe inadequada, pode gerar equívoco e prejuízos significativos. Portanto, é importante a informação de meta-dados, que inclua a escala de detalhe, a metodologia utilizada, o formato digital e outras informações referentes à padronização cartográfica (Jansle Vieira Rocha, Unicamp, em BRASIL, 2001, p. 335).

Outra preocupação que deve estar presente na definição da metodologia de um ZEE é o cuidado para viabilizar a reatualização do zoneamento. Afinal, a realidade é um processo 


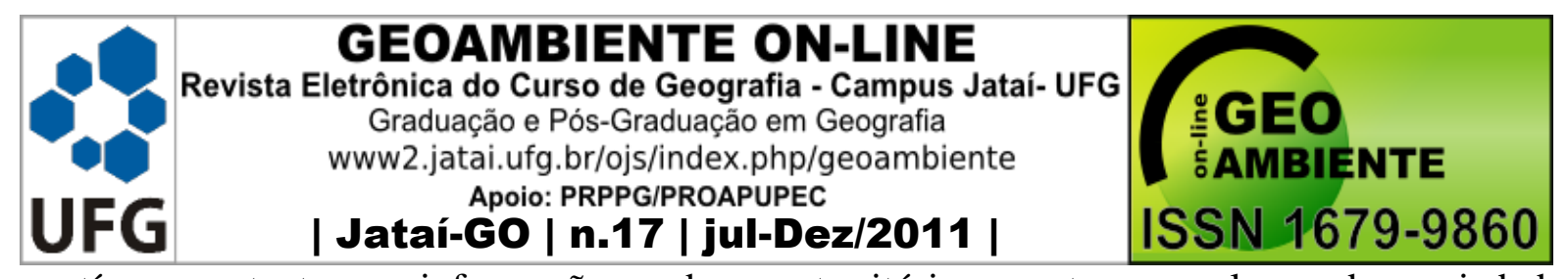

contínuo, e tanto as informações sobre o território quanto os valores da sociedade transformam-se (Cícero Antônio Lima, CVRD, em BRASIL, 2001, p. 368). Além disso, o desenvolvimento técnico-científico pode abrir novas possibilidades de aprimorar os trabalhos anteriores, potencializando sua utilidade. Uma preocupação estratégica relacionada a esse aspecto é que nem sempre a equipe realizadora do zoneamento é a que vai cuidar da atualização do mesmo (SANTOS, 2004, p. 63), o que demanda transferência de tecnológica, além da continuidade de acesso aos dados primários.

Os mapas gerados pelo ZEE podem ser considerados como modelos de explicação com uso intensivo de conhecimento. Para uma melhor qualidade na comunicação de explicações de modelos de uso intensivo de conhecimento, GINSBERG (1993, p. 193-208 e 388-392) aconselha que o usuário possa não apenas visualizar a resposta, mas sim obter, quando quiser, todo o caminho explicativo que levou até o resultado final. Esse ainda é um campo novo para os Sistemas de Informação Geográfica, embora seja uma preocupação tradicional na área de Sistemas Especialistas de Auxílio à Decisão. Portanto, não basta saber se uma área apresenta configurações favoráveis ou desfavoráveis, mas sim saber, quando preciso, o porquê de sua rotulação nesses termos.

Santos (2004, p. 65 e 135) relata situações em que índices complexos em zoneamentos trouxeram dificuldade de compreensão para a população e para os tomadores de decisão. Uma situação extrema poderia envolver até a manipulação ideológica desses índices, sob o véu de sua indecifrável sofisticação. Além disso, Santos também relata a dificuldade de relacionar esses resultados integrados complexos com as metas de ação assumidas pelas entidades executoras.

Uma maneira de ajudar a superar esses entraves seria acrescentar aos dados dos polígonos finais um meta-dado com a explicitação sobre o caminho lógico-explicativo percorrido até a conclusão. Entretanto, não é uma operação metodológica isenta de óbices, visto que as operações padrões de álgebra de mapas, usadas comumente no ZEE, utilizam-se de modelos rasters (matriciais), os quais possuem dificuldades em armazenar mais do que um tipo de informação por unidade de área.

\subsection{Diagnósticos socioeconômicos}

Fabré e Ribeiro (2007, p. 70) informam sobre o esforço realizado no ZEE da Amazônia Legal para avaliar a possibilidade de manutenção da Integridade Cultural das 


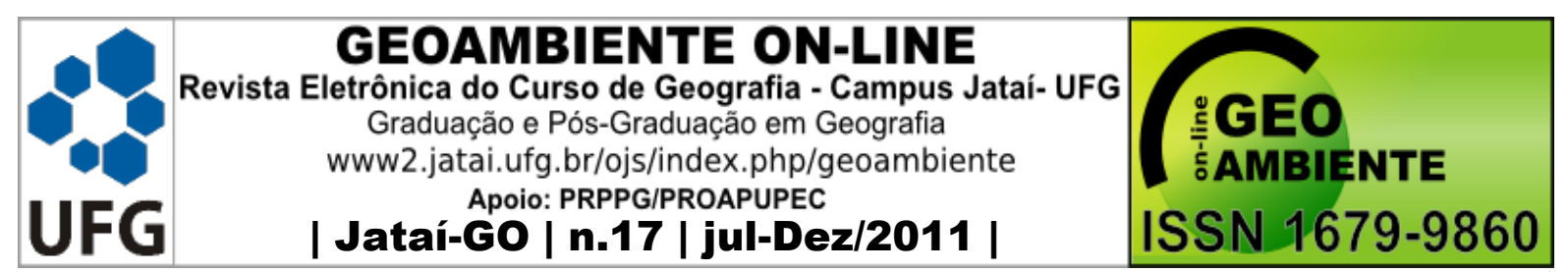

comunidades regionais. Desta forma, o ZEE incorpora o respeito à diversidade de culturas locais, sob uma concepção de que elas poderiam buscar o seu desenvolvimento autossustentável a partir de seus próprios valores e concepções de mundo (EMPRESA DE ASSISTÊNCIA TÉCNICA E EXTENSÃO RURAL DE MINAS GERAIS, 2004, p. 42-43). A inclusão dessa perspectiva no ZEE também é importante por abrir caminhos à análise sobre como os valores e visões de mundo de um grupo cultural podem influir na sua relação com o ecossistema (FABRÉ e RIBEIRO, 2007, p. 70). Partindo da perspectiva de que os conhecimentos e valores tradicionais podem trazer bons subsídios para uma melhor relação com a natureza, seria possível rastrear uma possível correlação entre a Integridade Cultural e Integridade Ecológica (BRASIL, 2007b, p. 232).

Todavia, a realidade cultural amazônica presta-se mais facilmente à delimitação de grupos culturais homogêneos. Isso se dá devido à presença significativa de comunidades tradicionais relativamente isoladas, como índios, ribeirinhos, extrativistas, entre outros.

Nas demais regiões do Brasil, é mais complexo o estudo de identidades culturais. Não significa que não haja grupos identitários, especialmente em virtude de interesses comuns, ou mesmo organizações sociais representativas. Contudo, a dificuldade se dá de maneira semelhante às reflexões que Seabra (1984, p. 14) e Claval (2002, p. 11-12) fazem sobre a possibilidade de se estudar o espaço geográfico capitalista contemporâneo por meio da metodologia de gêneros de vida, típica da escola regionalista francesa Para Claval (2002, p. 27-28), com o desenvolvimento da complexidade da sociedade contemporânea, aumenta a instabilidade de teorias, sistemas, valores e visões de mundo. Essa ressalva funda-se na constatação atual de que o meio urbano-rural tornou-se muito complexo, e nele as pessoas passam a ser cada vez mais poliatuantes, com estilos e modos de viver e produzir muito diferenciados. Nesse novo contexto, toda pessoa incorpora um universo diferenciado e com possibilidades múltiplas, sendo cada vez mais difícil exercer classificações de gêneros, classes, arquétipos ou comunidades homogêneas que sejam realmente fidedignas e coerentes.

Em bacias hidrográficas rurais, a prospecção das atividades econômicas da região darse-á, principalmente, através dos mapeamentos de uso do solo existentes, além de contato com as associações de produtores desta bacia hidrográfica e dos órgãos de assistência técnica rural locais. Deste modo procura-se identificar a tendência de estabilidade ou transformação de suas atividades atuais de uso do território, através da satisfação atual e expectativas, visões de oportunidade de negócio, anseios produtivos dos atores socioeconômicos e a viabilidade de 


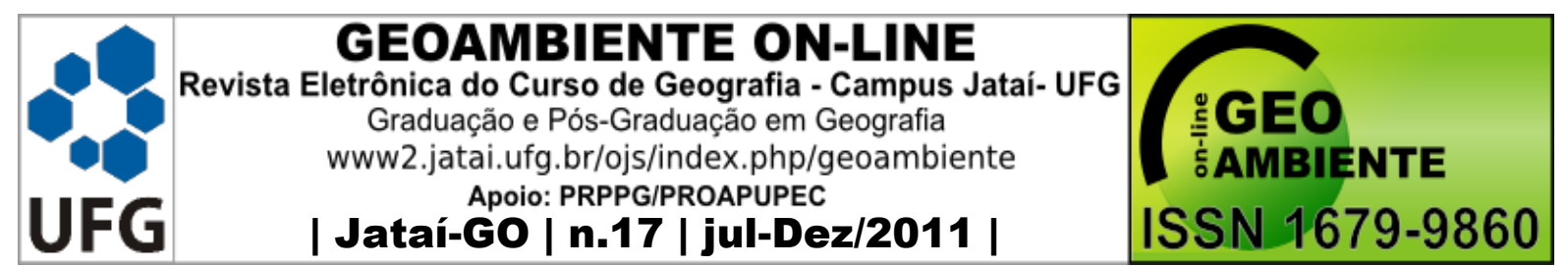

seus projetos futuros de atividade produtiva.

\subsection{A dimensão temporal e a construção de cenários}

A inclusão do tempo é um importante auxílio para não restringir-se a uma leitura estática do ambiente (SANTOS, 2004, p. 50). São de grande valor o estudo de como os processos desenvolveram-se em um determinado ambiente, além de ser útil procurar planejar como agir nos tempos futuros. Uma metodologia para se realizar este estudo é a construção de cenários. De uma maneira geral, os cenários enfocam três momentos:

- Passado: como o ambiente em questão se portaria originalmente, sem a interferência humana. Isso permite aproximar-se de quais são as condições ideais às quais o ecossistema da região se adaptou ao longo dos milhões de anos de evolução. Este cenário serve como uma meta ideal (porém utópica) de preservação ambiental; embora não possa ser alcançada, visto que devemos conciliar nela as atividades humanas, nos serve todavia como ponto de referência para o estabelecimento de metas e objetivos.

- Presente: como o ambiente porta-se atualmente, com suas configurações estáticas e dinâmicas das características e processos ecológicos. Devem ser estudadas tanto as condições dos ambientes naturais quanto do ambiente humano, e as interações entre ambos. As informações contidas nesse cenário vão dar ao planejador a consciência dos atuais problemas ambientais presentes na região.

- Futuro: um conjunto de cenários com previsões de evolução do quadro atual do ambiente de uma região. São computadas as tendências de ocupação territorial, crescimento urbano e rural, acúmulo de substâncias poluentes, desmatamentos, capacidade de recuperação do ambiente, e tantas mais quantas for possível, já que o objetivo é fazer uma previsão o mais abrangente possível, sendo tanto mais eficiente quanto mais variáveis recobrir.

Os cenários futuros tendenciais e alternativos são previstos como produto obrigatório do zoneamento-ecológico econômico (BRASIL, Decreto Federal n 4.297, de 2002, art. 12, inciso III). A simulação de cenários futuros de uso da terra tem sido bastante desenvolvida por meio de técnicas de modelagem de dados espaciais (CASTRO, 2005, p. 56). O estudo e a previsão de mudanças de uma paisagem pressupõem uma atenção a mudanças não apenas em sua forma (CASTRO, 2005, p. 35), mas também em sua estrutura e função (SANTOS, 2004, p. 53). Adentrando nesse aspecto, é interessante atentar que a mudança do uso da terra implica 


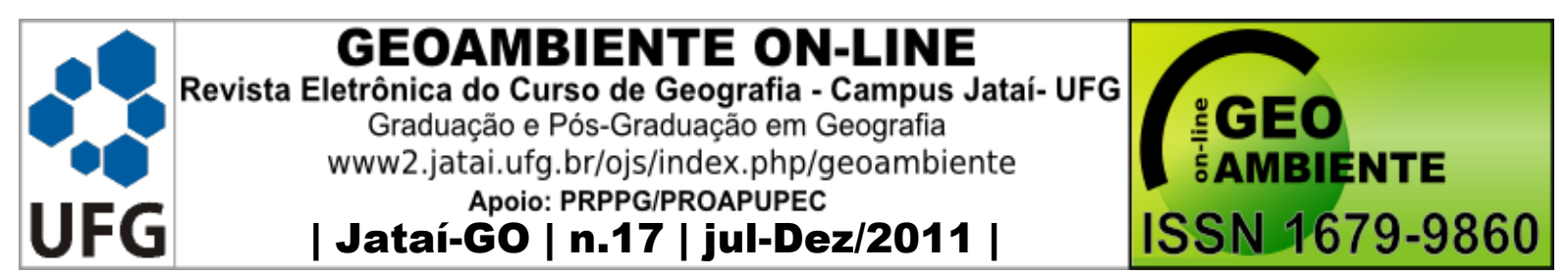

também em uma mudança dos valores e cultura da população que ocupa o respectivo território (SANTOS, 2004, p. 56).

O tempo a ser percorrido entre cada previsão pode variar tanto quanto os processos ecológicos que ocorrem em um meio ambiente, mas também devem se adaptar aos ciclos administrativos humanos, para que possa ser acompanhada sua evolução em paralelo com a atividade de gestão ambiental. Por exemplo, a degradação ou recuperação de uma floresta pode levar décadas, mas podem ser definidas etapas intermediárias que permitam acompanhar esses processos.

A modelagem dinâmica de frentes agrícolas tem usado principalmente modelos raster (matriciais), em função dos mesmos possibilitarem uma melhor flexibilidade na representação e tratamento de dados que variam gradualmente em um contínuo espacial (CASTRO, 2005, p. 48).

A partir da comparação de mapas demonstrando as classes de uso do território em diferentes períodos, é possível estimar as taxas médias de expansão ou contração das diversas classes de uso. O resultado é uma matriz de transição, ou seja, uma tabela que aponta as tendências de alteração do uso do solo (CASTRO, 2005, p. 57-58).

As taxas de variação de cada classe de uso são as variáveis base para indicar a evolução da paisagem, na modelagem dinâmica. Dentre essas taxas, a mais enfocada, sem dúvida é a taxa de desmatamento. Contudo, essa taxa não é contínua, e varia em função das variações econômicas, tais como o mercado de madeira nativa e de agropecuária, programas governamentais de crédito e colonização (CASTRO, 2005, p. 17-18), e difusão de tecnologias produtivas (SANTOS, 2004, p. 72). A taxa de desmatamento também é afetada por variáveis de conjuntura geral econômica, tais como escassez de emprego e queda de salários, que forçam a população a procurar novas alternativas de vida nas frentes de ocupação do território (CASTRO, 2005. p. 17).

Contudo, sempre existe um grau de incerteza na previsão de funcionamento dos processos humanos e ecológicos (BRASIL, 2007b, p. 233). Deve-se ter em conta que a modelagem dinâmica, como todo modelo científico, apresenta uma simplificação da complexidade real (SANTOS, 2004, p. 53 e 114).

Porém não basta apenas pensar a tendência de crescimento ou retração de cada classe de uso. É preciso estimar em quais áreas do espaço representado as classes de uso tem maior ou menor probabilidade de expandir-se. Um exemplo básico é o de que o desmatamento 


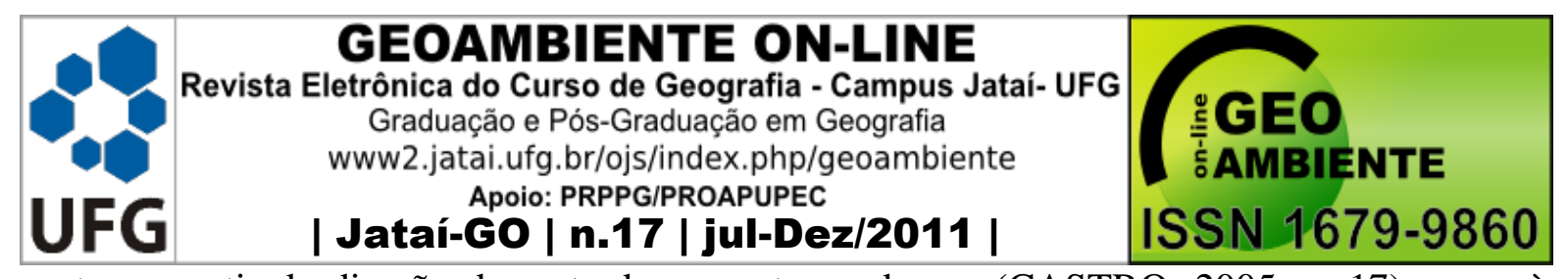

costuma partir da direção das estradas e centros urbanos (CASTRO, 2005, p. 17), rumo às áreas mais propícias às atividades agropecuárias. As variáveis de diferenciação espacial são chamadas de Pesos de Evidência, os quais definem as restrições ou favorecimentos a cada tipo de transição de uso do solo (CASTRO, 2005, p. 59).

As opções de modificação dos pesos de evidência dão origem ao diversos cenários. Estes podem ser divididos nos seguintes tipos:

- Cenários tendenciais (CASTRO, 2005, p. 56; SANTOS, 2004, p. 51), que indica o prosseguimento das forças atuais que atuam sobre a transformação do ambiente. Quando realizados em zoneamentos, normalmente procuram simular como os problemas atuais irão se agravar caso a sociedade e o governo mantenham a mesma postura que levou ao estado atual.

- Cenários Alternativos (CASTRO, 2005, p. 56), que podem incorporar:

- Cenários Normativos (MARQUES e SERFATY-MARQUES, 2007, p. 81; CASTRO, 2005, p. 56), limitando a transformação do ambiente ao permitido pelas normas legais.

○ Cenários Desejados ou Ideais (SANTOS, 2004, p. 51), expressando as aspirações da sociedade quanto ao seu ambiente, mas cientes das limitações existentes.

○ Cenário Exploratórios (SANTOS, 2004, p. 51) apresentando diversas alternativas de ocupação, para serem discutidas nos foros de decisão apropriados.

- Cenários Possíveis, ou de Consenso (SANTOS, 2004, p. 148): Expressam um acordo entre os diversos atores (comunidades, governo e setor produtivo) sobre como devem ser conduzidos o uso e a ocupação da região. Tanto os cenários desejados quanto os de consensos podem se valer de técnicas de planejamento e mapeamento participativo (CASTRO, 2005, p. 38-47; SANTOS, 2004, p. 54).

Não se pode esquecer que o ordenamento territorial futuro, embora seja em parte explicado pelo passado, será fruto de uma construção social (MARQUES e SERFATYMARQUES, 2007, p. 81). Ademais, deve-se sempre ter em mente que existe um grau de incerteza incorporado a qualquer processo ecológico e social (BRASIL, 2007b, p. 233). Nitsch (1998), citado por Castro (2005, p. 79) relata que não temos ainda noção das 


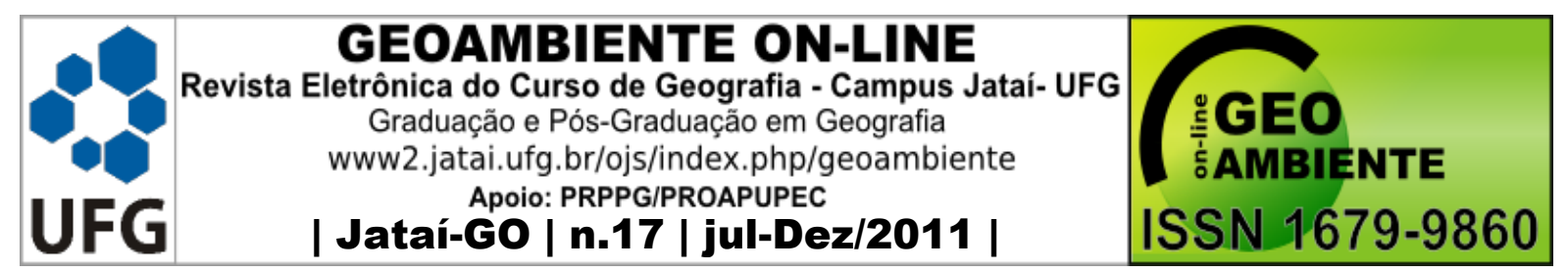

consequências exatas das mudanças climáticas globais e locais, bem como não sabemos como seguirá os curso do desenvolvimento científico-tecnológico - especialmente o biotecnológico - nem os padrões sociais que emergirão com a globalização; portanto, o ZEE não pode assumir um viés de determinismo ambiental e social.

O uso de termos como vocação natural e potencial social, bastante empregados em ZEEs, pode ser considerado como resquício de um viés da corrente determinista geográfica, a qual é constantemente criticada pelos geógrafos contemporâneos. (Pedro Pinchas Geiger, UFRJ, em BRASIL, 2001, p. 435). O grande desafio seria como conviver com a incerteza, sem deixar de planejar e agir. Portanto, ao invés de vocação e potencial natural/social, Nitsh (1998) citado por Castro (2005, p. 79-80) propõe que se procure uma abordagem mais afinada com a economia contemporânea, através da análise de riscos e oportunidades para os empreendedores.

\subsection{Discussão sobre a adaptação da metodologia a escalas menores}

O termo escala pode ser entendido como graduação ou categoria de análise (CASTRO, 2000, p. 59-60). Já em termos de reprodução cartográfica e arquitetônica, também pode se referir à correlação entre a representação de um objeto e seu tamanho real. Em cada escala, podemos observar elementos e estruturas diferentes, a partir de nosso aparato perceptivo e de instrumentos de análise (DOLLFUS, 1970, p. 1) ${ }^{2}$. É como se cada escala fosse uma maneira de enxergar o mundo, dando ensejo à criação de diferentes teorias, conforme o enfoque da escala de abordagem (CASTRO, 2000, p. 59-94). A variação de escalas de análise é um tema precioso para o geógrafo. É preciso cuidado ao comparar objetos de tamanhos muito diferentes, em escalas diferentes.

Santos (2004, p. 38) ressalta que todo zoneamento ambiental trabalha com recortes da realidade, proporcionados pela escala e pela metodologia empregada. Portanto, o planejador deve ter em mente que esse recorte implica simplificações e generalizações quanto ao ambiente real, que é deveras mais complexo. Também há casos em que os fenômenos são de uma escala de análise, porém a resposta (impacto ambiental) se dá em outra. Um exemplo é uma frente agrícola, determinada por tendências econômicas globais, mas que acaba por extinguir uma espécie endêmica a uma pequena região. Outras vezes a escala de tempo é que varia entre o fenômeno e a resposta, quando um processo de degradação só será perceptível

\footnotetext{
2 DOLLFUS, 1970, p. 1 - "Sabe-se também que, quando se muda de escala, os fenômenos mudam não
} somente de grandeza, mas, de natureza". 


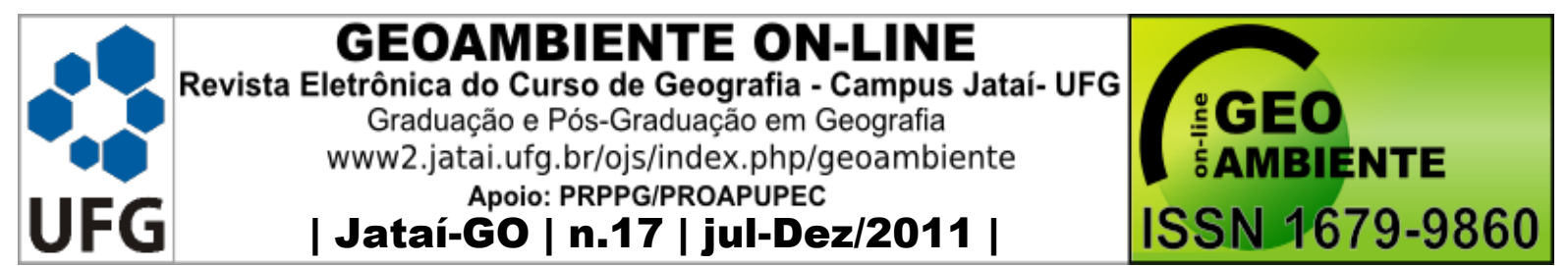

muito após o impacto inicial (SANTOS, 2004, p. 44).

Fabré e Ribeiro (2007, p. 61) afirmam que uma das maiores dificuldades de cientistas, ao planejar estudos com fins de subsídio à tomada de decisão, como o ZEE, é escolher qual será a escala e o detalhamento para o estudo de sistemas ambientais complexos. Isso envolveria questões como a opção pela escala mais adequada aos levantamentos, a frequência de coletas, e como os dados serão organizados e analisados (FABRÉ e RIBEIRO, 2007, p. 61). Para um cientista, o objetivo é "determinar a escala que ditará o quanto a extrapolação poderá ser feita sem perder a representação da heterogeneidade dos sistemas componentes" (SANTOS, 2004. p. 45-46). Contudo, a escala também deve adequar-se ao detalhamento demandado pelos produtos de auxílio à decisão (ou seja, adequar-se aos objetivos do usuário), bem como aos recursos de tempo e dinheiro disponíveis.

Marques e Serfaty-Marques (2007, p. 79) apresentam uma tabela demonstrando as escalas e abordagens utilizadas pela CPRM em sua experiência com Zoneamento EcológicoEconômico no Brasil (TABELA 2).

Tabela 2 - Principais características escalares dos Projetos de ZEE orientados pela CPRM.

\begin{tabular}{|c|c|c|c|}
\hline Escala & Nível de Abordagem & Variável Principal & Esfera Política \\
\hline $\begin{array}{c}\text { 1:5.000.000 } \\
/ 1: 250.000\end{array}$ & $\begin{array}{c}\text { Megadiagnóstico / } \\
\text { zoneamento nacional / } \\
\text { continental }\end{array}$ & Grandes vocações territoriais & Geopolítica \\
\hline $1: 1.000 .000$ & $\begin{array}{c}\text { Macrodiagnóstico / } \\
\text { zoneamento (regional) }\end{array}$ & Sistemas territoriais produtivos & $\begin{array}{c}\text { Macropolíticas e } \\
\text { políticas regionais }\end{array}$ \\
\hline $1: 250.000$ & $\begin{array}{c}\text { Mesodiagnóstico } \\
\text { (regional) }\end{array}$ & $\begin{array}{c}\text { Vulnerabilidade ambiental e } \\
\text { potencialidade econômica dos } \\
\text { sistemas }\end{array}$ & Políticas Estaduais \\
\hline $1: 100.000 /$ & Microdiagnóstico & $\begin{array}{c}\text { Sustentabilidade ambiental e } \\
\text { econômica dos microssistemas }\end{array}$ & $\begin{array}{c}\text { Políticas } \\
\text { Municipais }\end{array}$ \\
\hline
\end{tabular}

Adaptado de Marques e Serfaty-Marques (2007, p.79)

A realização do ZEE em diferentes escalas suscita a questão sobre qual deverá ser o critério de delimitação da área de zoneamento. Existem vários critérios utilizados, desde uso de limites territoriais, cruzamento de mapas temáticos para estabelecimento de áreas homogêneas, unidades naturais identificáveis, áreas de influência, proteção ou amortecimento por modelos de distância relativa, entre outros. Outras estratégias mais complexas primam por utilizar esses critérios de forma conjugada (SANTOS, 2004, p. 43). 


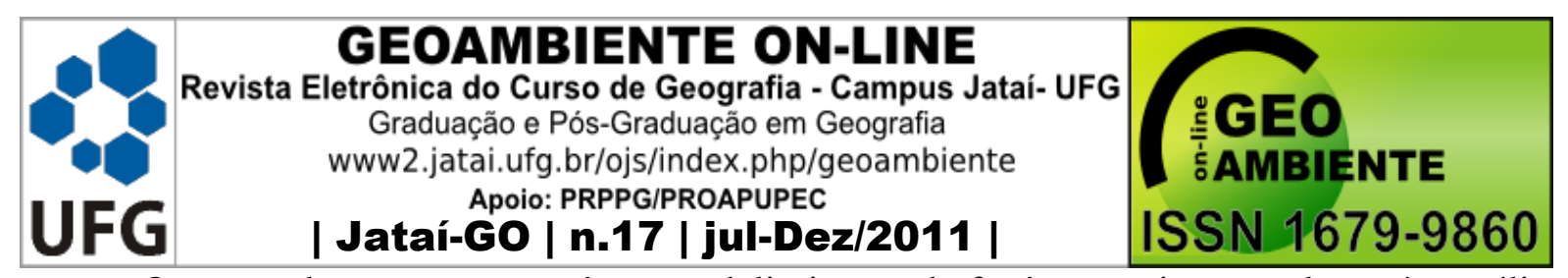

Outra evolução contemporânea na delimitação de fenômenos interescalares é a análise de fractais (KOHLER, 2002, p. 27-28), em que certo tipo de feição geométrica repete-se de maneira similar em diversas escalas. Exemplos desse tipo de fenômeno são as bacias hidrográficas e as feições geomorfológicas, tratadas a seguir.

Um modelo clássico de delimitação é o de bacia hidrográfica. O enfoque do planejamento de Bacias Hidrográficas mostra-se potencialmente bastante eficaz na gestão ambiental de territórios, visto que estas podem ser pesquisadas como sistemas naturalmente delimitados (SANTOS, 2004. p. 40), onde há trocas de matéria, energia e informação bem definidas (como escoamento superficial na saída da sub-bacia, precipitação hídrica e de energia solar, erosão, migração de animais e de seres humanos, etc.). Outra vantagem da gestão de Bacias Hidrográficas é que ela permite o trabalho em múltiplas escalas, desde grandes rios nacionais que atravessam diversos Estados e deságuam no oceano, até bacias de pequenos riachos dentro de uma propriedade rural. Essas diferenças de escala permitem que as bacias hidrográficas sejam usadas desde o ordenamento territorial em grandes planos setoriais governamentais, até o planejamento das atividades de produtores rurais em suas propriedades particulares.

O enfoque de zoneamento de bacias hidrográficas ganhou relevância com o agravamento de conflitos relacionados ao uso de recursos hídricos. Com fins de permitir a gestão de situações de escassez e poluição da água, estruturou-se o Sistema Nacional de Recursos Hídricos, por meio da Lei Federal $n^{\circ}$ 9433, de 1997. Com isso, as bacias hidrográficas passaram a contar com novos instrumentos de gestão, como comitês de bacia, agências de águas, outorga e cobrança por uso da água, enquadramento de corpos d'água, planos diretores de bacia hidrográfica, sistemas de informação de recursos hídricos, entre outros. Além disso, a Resolução Conama 01/1986 também já denominava que os Estudos de Impacto Ambiental deveriam "definir os limites das áreas geográficas a ser direta ou indiretamente afetada pelos impactos, denominada de área de influência do projeto, considerando, em todos os casos, a bacia hidrográfica na qual se localiza" (art. 50, item III). Nesse aspecto, um ZEE de bacia hidrográfica facilitaria em muito sua inter-relação com os demais instrumentos já existentes para gestão de bacias (Raimundo Garrido, SRH/MMA, em BRASIL, 2001, p. 179-180).

Inobstante, o recorte de ZEE para bacias hidrográficas pode implicar certas limitações e dificuldades. Uma delas é o caso dos aquíferos subterrâneos, que podem ser compartilhados 


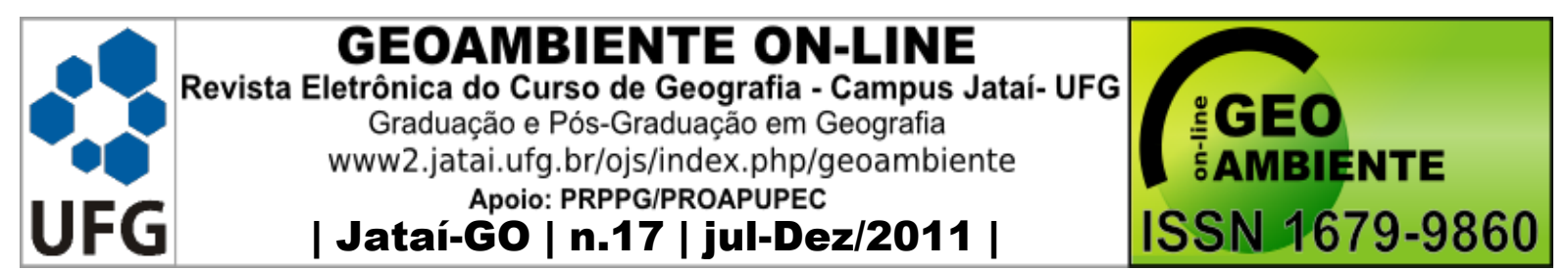

por diversas bacias vizinhas (ARRAES, 2008, p. 8-10). Além disso, as tecnologias modernas permitiram às redes de ocupação humana estabelecer esquemas de ocupação de uso de solo que transcendem os limites naturais tais quais as bacias hidrográficas (SANTOS, 2004, p. 41,42). Um exemplo evidente seria a transposição de bacias hidrográficas. Mas não também as redes de transporte e comunicação, bem como a expansão e atração nuclear da malha urbana, as quais geram padrões de ocupação do território que não podem ser captados por análise isolada de bacias. Essa questão é particularmente significativa na região Sudeste do Brasil, uma vez que é onde se encontra a rede urbana e industrial mais densa (Tereza Cardoso da Silva, UFBA, em BRASIL, 2001, p. 419). Além disso, existe a dificuldade metodológica associada ao fato de que muitas informações administrativas e censitárias estão disponíveis para os recortes administrativos (Estados, Municípios, Distritos, etc.) e não são facilmente transpostas para os limites de bacias (SANTOS, 2004. p.42).

De modo complementar à delimitação de bacias hidrográficas, Santos (2004, p. 78) considera que a delimitação de áreas homogêneas geomorfológicas é essencial ao planejamento ambiental. Justifica-se essa preocupação porque muitas formas de ocupação do solo estão subordinadas às condições de declividade, estabilidade e rugosidade do relevo. $\mathrm{O}$ zoneamento geomorfológico é utilizado com facilidade como recortes de bacias hidrográficas, pois estas últimas prestam-se bem a compartimentações diferenciadas de relevo desde as cabeceiras até a foz do curso d'água.

Thelma Krug (INPE, em BRASIL, 2001, p. 32-33) observa que há uma grande demanda de aproximação da metodologia do ZEE aos problemas socioambientais das comunidades locais, e que a oportunidade poderia ser bem aproveitada na ocasião de ZEEs em escala menor. A referida autora cita que, no ZEE do Amapá, procurou-se fazer essa aproximação, através da inserção das experiências das comunidades locais em uma etapa posterior à do macrozoneamento.

Contudo, a forma de percepção de problemas ambientais é bastante diferenciada entre população local e planejadores territoriais (Ivan Maglio, Secretaria de Planejamento do Município de São Paulo, em BRASIL, 2001, p. 159). O planejador procura regionalizar fragilidades ambientais, o que é um conceito de difícil entendimento para a população de menor formação técnica. Todavia, a população local possui uma rica experiência de problemas cotidianos, a qual conta com uma riqueza de detalhes e valores humanos que é difícil de conciliar com as restritas variáveis do zoneamento. Além disso, há o risco da 


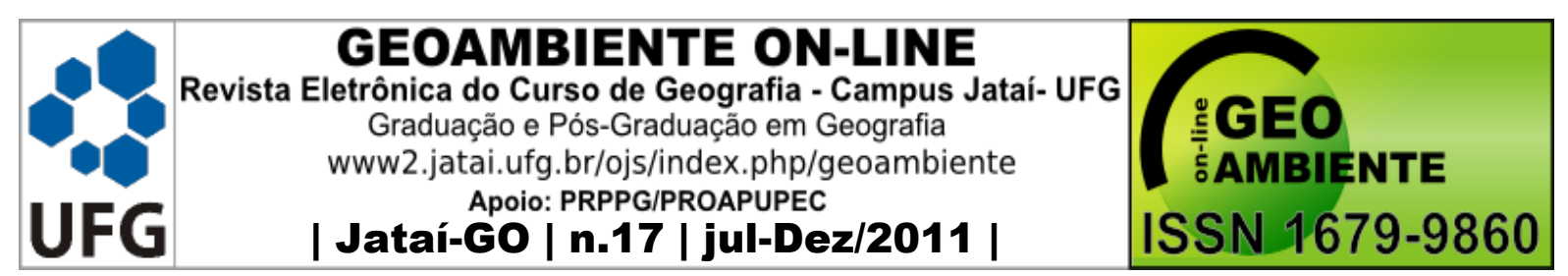

redução à escala dos problemas locais tornar-se uma disputa de interesses particulares, sem uma noção regional de desenvolvimento sustentável. É o que bem expressa Santos (2004, p. 167), ao escrever que a incorporação de experiências pessoais "se por um lado pode ser um fator enriquecedor para o conhecimento da complexidade da área, para melhor reflexão sobre ela e para o diálogo, por outro pode encapsular o partícipe em seu próprio universo, dificultando a incorporação de outras visões".

O estudo dos fenômenos biológicos e ecossistêmicos capta fenômenos diferenciados a partir da escala. FABRÉ e RIBEIRO (2007, p. 64) apresentam, na Tabela 3, uma esquematização sobre os diferentes fenômenos envolvidos em cada escala de estudo. Com efeito, essa diferenciação epistemológica implicará diferentes percepções sobre a caracterização da biodiversidade:

Na escala global e provincial, a diversidade está relacionada com os processos de especiação, radiação adaptativa, extinção em massa, ou seja, processos relacionados ao tempo evolutivo. Nas escalas regional e de paisagem, os processos que explicam as características de biodiversidade estão relacionados, por exemplo, com tipos vegetacionais, nos quais a dispersão das espécies e seleção de habitats são importantes. (FABRÉ e RIBEIRO, 2007, p. 64)

No que compete à utilização dos recursos bióticos, Fabré e Ribeiro (2007, p. 68) percebem que a percepção sobre o uso extrativista de recursos da biodiversidade se dá com mais intensidade em escalas menores. Entretanto, contrastam que, no que diz respeito ao potencial econômico dos recursos biológicos (inclusive genéticos), as escalas mais adequadas de aferição vão desde as mesoescalas, até análises globais de mercado.

O mapeamento de uso do solo também é muito sensível à delimitação de escala (SANTOS, 2004, p. 98). Grandes monoculturas e minerações podem ser delimitadas em escalas grandes. Contudo, outros padrões de ocupação, como agricultura familiar, vilas rurais, chacreamentos, malha urbana, e extrações de areia são analisáveis apenas em escalas muito refinadas. 


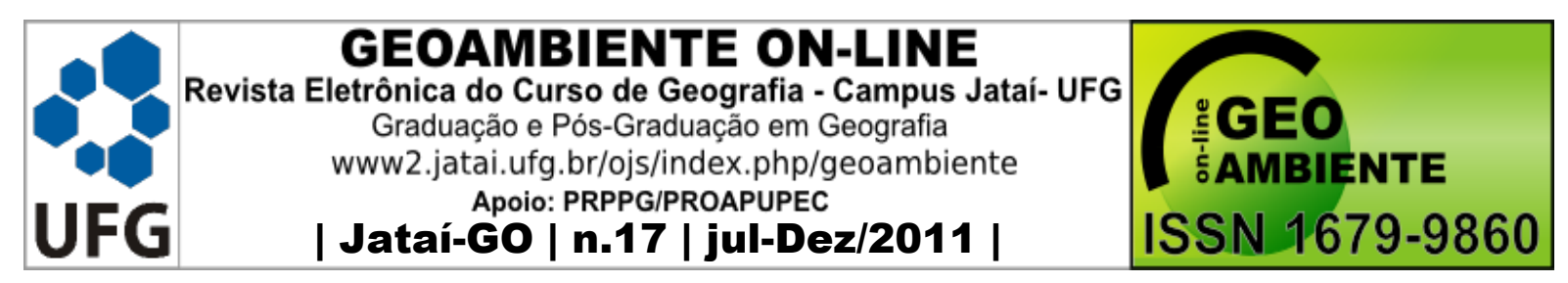

Tabela 3 - Níveis hierárquicos de organização ecológica, com características chave para avaliação da Integridade Ecológica.

\begin{tabular}{|c|c|c|c|c|}
\hline Escala & $\begin{array}{c}\text { Nível } \\
\text { Hierárquico }\end{array}$ & Estrutura & Função & Composição \\
\hline $\begin{array}{l}\text { Region } \\
\text { al }\end{array}$ & $\begin{array}{l}\text { Unidade } \\
\text { Paisagística }\end{array}$ & $\begin{array}{l}\text { Região, } \\
\text { heterogeneidade } \\
\text { espacial, patch size, } \\
\text { forma, distribuição, } \\
\text { fragmentação, } \\
\text { conectividade }\end{array}$ & $\begin{array}{c}\text { Estabilidade e } \\
\text { constância de } \\
\text { diferentes tipos de } \\
\text { patch, erosão, } \\
\text { processos } \\
\text { geomorfológicos e } \\
\text { hidrológicos, resposta } \\
\text { aos distúrbios naturais } \\
\text { ou antrópicos }\end{array}$ & $\begin{array}{l}\text { Identificação, } \\
\text { distribuição e } \\
\text { riqueza dos } \\
\text { diferentes tipos de } \\
\text { patch }\end{array}$ \\
\hline Local & $\begin{array}{l}\text { Ecossistema } \\
\text { / } \\
\text { Comunidad } \\
\mathrm{e}\end{array}$ & $\begin{array}{l}\text { Substrato e condições } \\
\text { de solo, relevo, } \\
\text { cobertura vegetal, } \\
\text { distribuição de } \\
\text { características físicas, } \\
\text { abundância e } \\
\text { distribuição de } \\
\text { ambientes aquáticos, } \\
\text { qualidade de água } \\
\end{array}$ & $\begin{array}{c}\text { Biomassa, } \\
\text { produtividade, } \\
\text { decomposição, taxas } \\
\text { de ciclagem de } \\
\text { nutrientes, de fluxo de } \\
\text { energia, de } \\
\text { colonização, de } \\
\text { imigração e de } \\
\text { emigração. }\end{array}$ & $\begin{array}{l}\text { Riqueza específica, } \\
\text { diversidade de } \\
\text { guildas, presença ou } \\
\text { ausência de espécies } \\
\text { chaves, curvas de } \\
\text { dominância de } \\
\text { espécies, } \\
\text { coeficientes de } \\
\text { similaridade } \\
\end{array}$ \\
\hline
\end{tabular}

Fonte: Adaptado de Fabré e Ribeiro (2007, p. 64).

\subsection{Compara as demais experiências de ZEE do Brasil com a realidade do Sudeste}

\section{Brasileiro}

Durante a história do ZEE no Brasil, a Amazônia Legal foi enquadrada como prioridade político-estratégica. Isso levou as discussões metodológicas do ZEE a adaptaremse ao contexto dessa região. Trata-se de uma região onde:

o papel do Poder Público na condução do desenvolvimento é específico e decisivo, onde a questão dos recursos naturais se impõe, onde existem amplos espaços ainda vazios, onde a organização geográfica em áreas é um elemento muito importante e onde a organização em redes ainda é pouco desenvolvida (Pedro Pinchas Geiger, UFRJ, em BRASIL, 2001, p. 434).

Posteriormente, ao tomar força o processo de ZEE nas demais regiões brasileiras, requer-se um esforço de reflexão para verificar em que pontos a metodologia amazônica conduz a resultados fidedignos ou não. As diferenças entre as áreas mais antropizadas do 


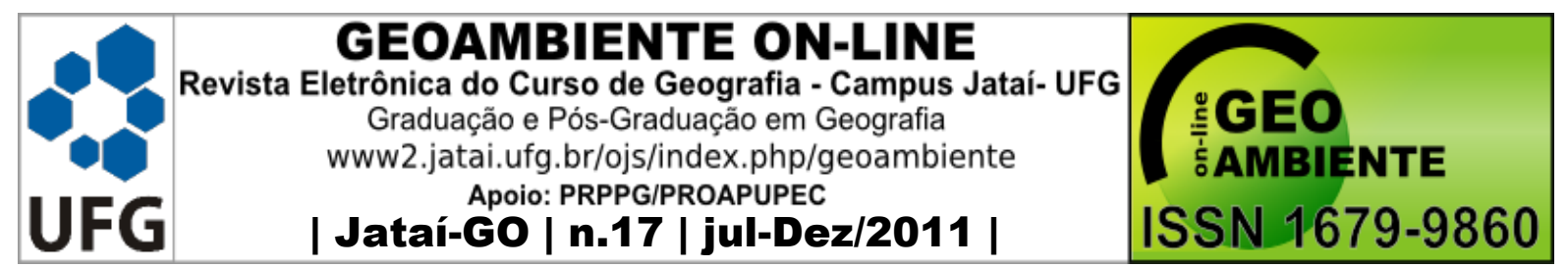

restante do país e as áreas conservadas (porém em risco) da Amazônia levaram a Maurício Otávio de Mendonça Jorge (CNI, em BRASIL, 2007a, p. 44-45) a propor um corte metodológico entre o ZEE do Bioma Amazônico e o do restante do país.

Com efeito, o cenário deparado por um ZEE no Sudeste brasileiro possui características singulares, se comparado ao restante do Brasil. Trata-se de uma região com um histórico de colonização mais denso, onde em cada região sobrepuseram-se diversos ciclos de ocupação, tais como os de cana de açúcar, pecuária de carne e leite, café, mineração, agronegócio, urbanização e industrialização (Tereza Cardoso da Silva, UFBA, em BRASIL, 2001, p. 417-419). Portanto, a visualização dos avanços e retrocessos de determinada forma de ocupação do solo não é tão evidente quanto, por exemplo, na fronteira de desmatamento da floresta amazônica (Ubiratan Porto dos Santos, UFRJ, em BRASIL, 2001, p. 256).

Mais que uma ocupação frente às terras virgens, a fronteira agrícola tecnológica do Sudeste opera na forma de ciclos de inovação, mais adaptados às tecnologias e forças econômicas vigentes (BITTENCOURT, 2000, p. 27). Essa sobreposição histórica de ciclos ocasiona a presença de vários fragmentos de ocupação do solo, relacionados a contextos econômicos pretéritos, e que já não são economicamente nem ecologicamente viáveis. Portanto, o ZEE em regiões do Sudeste possui a oportunidade de identificar essas disfunções de ocupação do território e propor um modelo mais otimizado e racional de uso do solo.

Outra dificuldade para um ZEE da região sudeste é por tratar-se da área mais urbanizada do Brasil. Dias (1995, p. 145-162) e Haesbaert (2000, p. 165-205) apontam que, com o avanço da modernização capitalista nos processo de formação socioespacial, uma geografia de redes passa a ser talvez mais significativa que uma geografia de espaços extensos. Como efeito, as redes globalizadas de transporte, comércio e informação formam padrões cada vez mais complexos na região sudeste, de modo que essa estrutura (no sentido dos conceitos de Milton Santos, estudados por CORRÊA, 2000, p. 29) tenha um papel importante na explicação das formas de ocupação (Adma Figueiredo, IBGE, em BRASIL, 2001, p. 414). Essa análise de estruturas de redes e fluxos é um desafio para a metodologia do ZEE, visto que esta foi desenvolvida basicamente a partir de técnicas de álgebra de mapas rasterizados (matriciais).

Portanto, as tendências de ocupação do solo no Sudeste são pouco explicadas por processo lineares de ocupação (Pedro Pinchas Geiger, UFRJ, em BRASIL, 2001, p. 435). Uma teoria mais aceita que pode lançar boas luzes sobre o processo de ocupação territorial no 


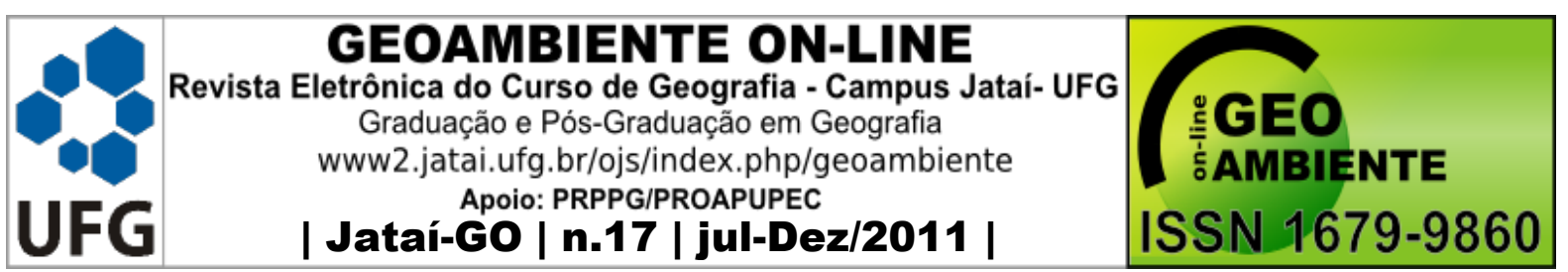

Sudeste e, em especial, em Minas Gerais, é o modelo de Reconcentração Poligonal (SANTOS, 2002, p. 42-43). Segundo essa concepção, com a modernização das redes tecnológicas capitalistas, certas funções produtivas e investimentos de expansão começam a afastar-se dos grandes centros produtivos - inicialmente o setor primário, e depois o secundário -, enquanto os serviços de alto capital humano concentram-se exponencialmente nas grandes metrópoles (CASTRO, 2002, p. 181-222).

Uma característica da Região Sudeste, que não pode deixar de ser levada em conta, é a forte pressão de uso e ocupação do solo realizada por empreendimentos privados. Ou seja, uma região onde a força do capital humano avança sobre o capital latente dos recursos naturais (Pedro Pinchas Geiger, UFRJ, em BRASIL, 2001, p. 434-435). Quanto a esse aspecto, Antônio Theodorivcs (CPRM, em BRASIL, 2001, p. 234) recomenda que as diretrizes fornecidas pelo zoneamento foquem mais a recomendação e indução de uso do solo, em vez de verter pelo caminho da restrição absoluta. Justifica-se essa flexibilização pela dificuldade encontrada pelo Poder Público em barrar esses processos de ocupação, sendo mais sensato procurar aconselhar e guiar a ocupação da maneira mais sustentável possível.

A região Sudeste, inclusive o Estado de Minas Gerais, possui a vantagem já possuir um grande acervo de estudos e dados ambientais publicados. Contudo, Antônio Theodorovics (CPRM, em BRASIL, 2001, p. 229) ressalta que existem muitas dificuldades em acessar e integrar essa gama de informações disponíveis. Um dos problemas apontados é a complexidade inerente de cada trabalho, o que, se por um lado dificulta a análise por pessoal capacitado, praticamente inviabiliza a utilização desses estudos pela população e por gestores com formação em outras de conhecimento.

Outra dificuldade é que grande parte dos trabalhos encontram-se em meio analógico, e mesmo os que se encontram em meio digital estão dispersos em diversos formatos e padronizações cartográficas (Ricardo Cartaxo Souza, INPE, em BRASIL, 2001, p. 303). As iniciativas de estruturar núcleos de informação georreferenciada, como o Sistema Integrado de Informação Ambiental - SIAM - em Minas Gerais, são passos importantes para potencializar a integração de informação por geoprocessamento.

\subsection{Proposição de uma metodologia de Zoneamento Ecológico Econômico para Frentes}

\section{Agrícolas de Irrigação do Sudeste Brasileiro}

A procura de novas formas que possam conciliar o desenvolvimento agrícola com a utilização sustentável dos recursos naturais é um dos desafios mais prementes para a ciência 


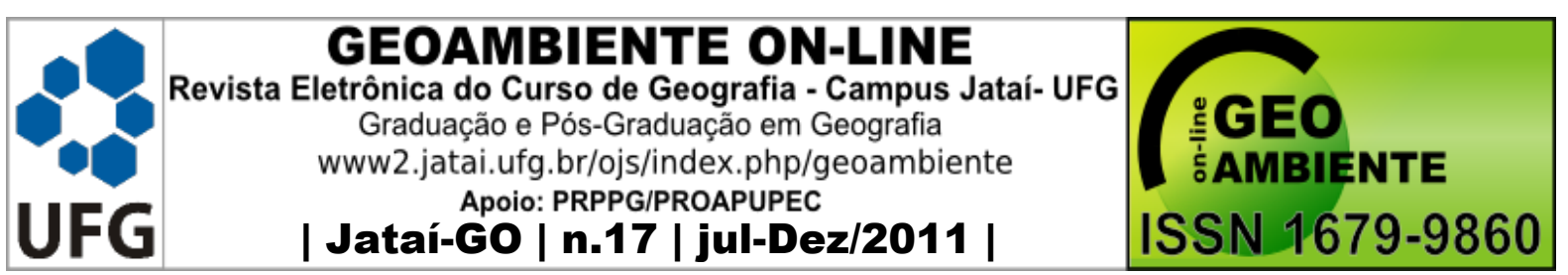

brasileira. Devido à demanda econômica por ampliação constante das fronteiras agrícolas, a manutenção dos padrões produtivos atuais contribuirá para uma pressão gradativamente maior sobre os ecossistemas nativos brasileiros. Ademais, o uso intensivo dos recursos naturais compromete outras oportunidades de uso múltiplo. O limite proporcionado pela escassez de água em bacias hidrográficas agrárias é um limitador para a expansão de novas frentes irrigadas nessas regiões.

Propõe-se, para as bacias hidrográficas agrárias do Sudeste, que seja realizado um percurso da história de ocupação do solo dessa bacia hidrográfica, procurando mostrar como as modificações de uso do solo e de tecnologia produtiva interferiram no balanço hídrico natural e no ecossistema como um todo. Para tanto, podem ser utilizados levantamentos de vegetação e uso dos solos elaborados para essa bacia em diversos períodos históricos, bem como pela análise de imagens de sensoriamento remoto. Esses usos serão comparados com um mapeamento de vegetação e uso dos solos atuais.

Esse processo de ocupação do solo pode então ser confrontado com o conhecimento existente sobre os aquíferos subterrâneos e superficiais, cobertos por monitoramentos e pesquisas de Hidrologia e Hidrogeologia. Pretende-se com isso estabelecer relações entre os sistemas agroeconômicos existentes na bacia e o ciclo hidrológico como um todo. Devem ser enfocados, primariamente, (1) o uso consuntivo de água, (2) a redução de infiltração da água no solo por ocupação de zonas de recarga e (3) o impacto da drenagem de veredas, lagoas marginais e áreas de inundação. Todos esses estudos serão comparados com o processo de ocupação de uso do solo, e disso espera-se chegar a conclusões sobre o relacionamento entre a agricultura (viés econômico) e os recursos hídricos (viés ecológico).

A Figura 1 demonstra, na forma de um diagrama de atividades baseado na linguagem UML (BOOCH; RUMBAUGH; JACOBSON, 1999), os passos a serem seguidos. Contudo, não deve ser perdido de vista o paradigma sistêmico de análise ambiental, para que não se caia no risco de chegar a explicações reducionistas ou mesmo fugidias à realidade, por não analisar outros fatores pertinentes. Entre esses fatores, está toda a gama de relações ambientais e econômicas que permeiam o objeto de estudo em comento. A esse eixo central proposto, podem ser integrados os demais estudos, como potencial erosivo, aptidão agrícola, estudos sociológicos, vulnerabilidade biótica, dentre outros. Portanto, a relação entre os diversos estudos deve incorporar, na medida do possível, as relações de dinâmica temporal e espacial entre os diversos subsistemas enfocados na bacia hidrográfica. Por exemplo, os 


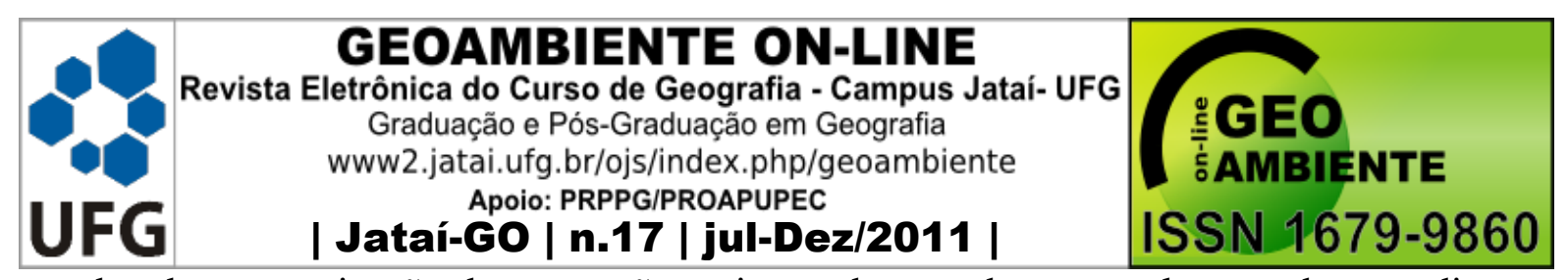

estudos de caracterização da vegetação nativa podem ser bem complementados por diversas metodologias de estudo de Ecologia de Paisagem. Dentre elas, estão as análises de conectividade, fragmentação e efeito de borda (BORGES et al., 2004, p. 23-37), bem como estudos dos ciclos biogeoquímicos (FORTI, 2003, p. 4-7). A compreensão das relações entre a flora, fauna, recursos naturais e paisagem são salutares para a sustentabilidade ecológica das bacias hidrográficas.

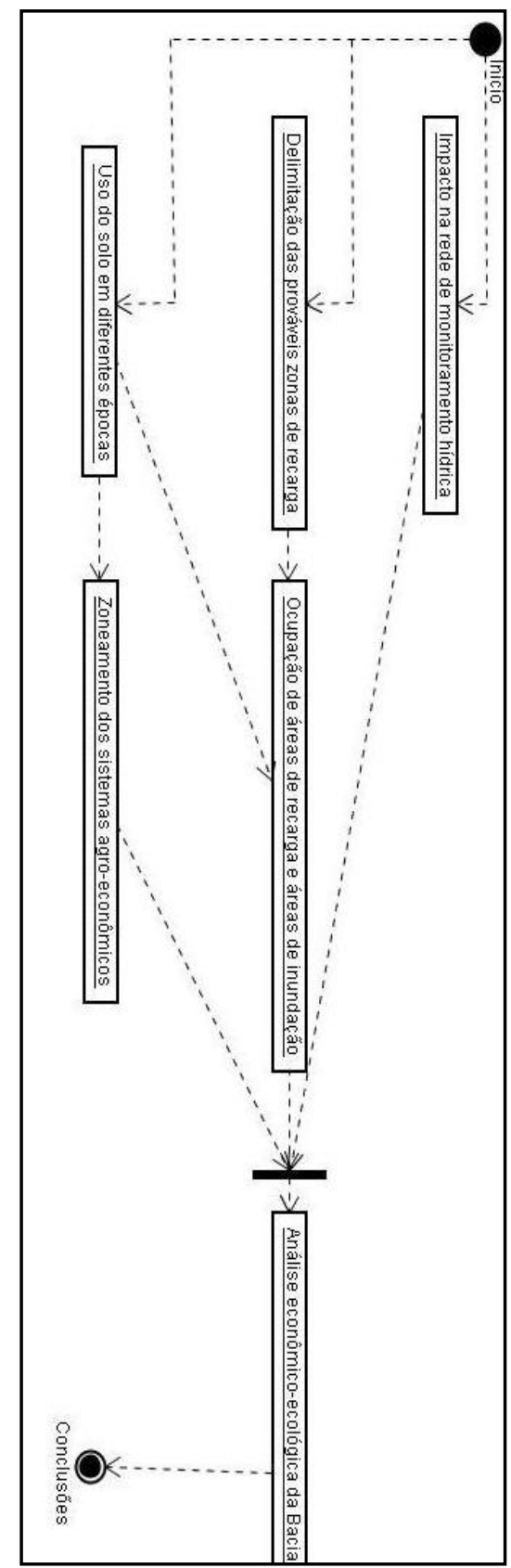

Figura 1 - Diagrama de Atividades explicitando os passos metodológicos propostos para estudos no contexto do Zoneamento Ecológico Econômico de bacias agrárias do Sudeste brasileiro. 


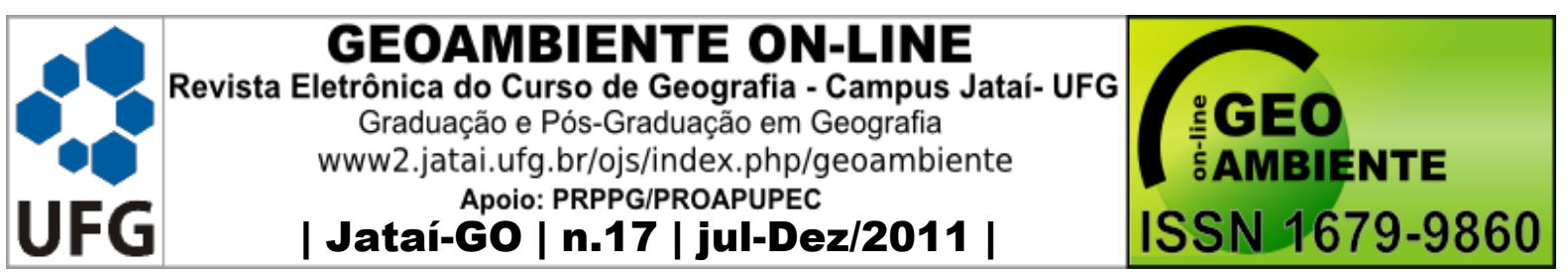

\section{Conclusões}

As particularidades de ocupação do Sudeste brasileiro justificam a necessidade de se repensar as metodologias de Zoneamento Ecológico-Econômico para essa região. A dinâmica econômica, os processos históricos de ocupação e as peculiaridades ambientais do Sudeste formam um sistema de interação sociedade-ambiente em que a utilização dos recursos naturais e os impactos ambientais nem sempre são bem representados pelas atuais metodologias do ZEE.

Por meio da incorporação de abordagens de outras ciências, e lançando mão das novas tecnologias de sistemas de informação strictu sensu e geográfica, é possível superar em parte as dificuldades identificadas até o momento. Também é necessário uma atenção e diálogo amplos para com os atores que participam da ocupação do território, para que se possam elaborar cenários futuros plausíveis com as propostas de desenvolvimento sustentável.

Ademais, ressalta-se que as diferentes escalas de zoneamento, bem como características especiais de cada área zoneada, podem justificar metodologias diferenciadas para se chegar a um ZEE mais coerente com a realidade estudada. O presente artigo expôs, nesse sentido, uma proposta metodológica possivelmente mais adequada para o zoneamento ecológico-econômico de bacias hidrográficas ocupadas por frentes agrícolas irrigadas. No caso, a perspectiva da dinâmica hidrológica e do impacto sobre as relações espaciais fitoecológicas se apresentaram como alternativas viáveis para evidenciar melhor as interações entre os sistemas naturais e antrópicos atuantes.

\section{BibliografiaS}

ARRAES, T.M. Proposição de Critérios e Métodos para Delimitação de Bacias Hidrogeológicas. 2008. 125p. Dissertação de Mestrado. Instituto de Geociências - UNB. Brasília, 2008.

BANCO DE DESENVOLVIMENTO DE MINAS GERAIS - BDMG - MINAS GERAIS. Minas Gerais do Século 21. vs. 1 a 9. Belo Horizonte, Banco de Desenvolvimento de Minas Gerais - BDMG. Disponível em: www.bdmg.mg.gov.br/estudos/estudos_mg.asp.

BITTENCOURT, Maurício Vaz Lobo. Influência da Tecnologia e de Fatores Macroeconômicos sobre a Agricultura. Curitiba, PR: CMDE/UFPR, 2000, p. 27 Disponível em: 


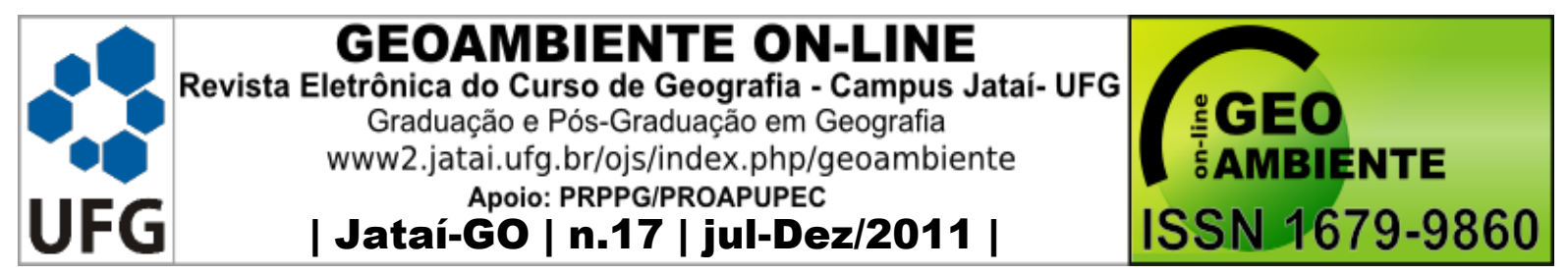

http://www.economia.ufpr.br/publica/textos/2000/txt1000\%20Mauricio\%20Bittencourt\%20In

fluencia.doc, em outubro de 2008.

BOOCH, G., RUMBAUGH, J., JACOBSON, I. - The Unified Modeling Language User Guide, UML - 6th printing, Addison Wesley Publishing Company, Massachusets, EUA, 1999.

BORGES, Luís Fernando Rocha; SCOLFORO, José Roberto; OLIVEIRA, Antônio Donizette de; MELLO, José Márcio de; ACERBI JUNIOR, Fausto Weimar; FREITAS, Guilherme Dias de. Inventário de Fragmentos Florestais Nativos e Propostas para seu Manejo e da Paisagem. Revista Cerne, Lavras, v. 10, n. 1, p. 22-38, jan./jun. 2004.

BRASIL. Decreto Federal no 4.297 de 10 de julho de 2002 - Regulamenta o art. 9º , inciso II, da Lei $\mathrm{n}^{\mathrm{o}}$ 6.938, de 31 de agosto de 1981, estabelecendo critérios para o Zoneamento Ecológico-Econômico do Brasil - ZEE, e dá outras providências. Diário Oficial da União, Brasília, 11.7.2002.

BRASIL. MMA - Ministério do Meio Ambiente Agenda 21 Brasileira: bases para a discussão - Novaes, W. (coord) - MMA/PNUD - Brasília, 2000

BRASIL. MMA - Ministério do Meio Ambiente - Metodologia de Zoneamento EcológicoEconômico para a Região Sudeste: Transcrição de debates - Brasília, 2001, 450p.

BRASIL. CÂMARA DOS DEPUTADOS. Debate sobre Zoneamento-Ecológico Econômico. Comissão de Meio Ambiente e Desenvolvimento Sustentável. Edição: Departamento de Taquigrafia, Revisão e Redação, Núcleo de Redação Final em Comissões. 2007a. 53p.

BRASIL. Caderno Temático: Biodiversidade no Âmbito do Zoneamento EcológicoEconômico - Ministério do Meio Ambiente, Secretaria de Políticas para o Desenvolvimento Sustentável. Programa de Zoneamento Ecológico Econômico. 2007, 240p.

CASTRO, Antônio Barros de. O Quadro Internacional e a Evolução Recente da Economia Brasileira. In: Minas Gerais no Século XXI, vol. 1. O ponto de Partida, Belo Horizonte, 2002, p.181-222.

CASTRO, Frederico do Valle Ferreira de Castro - A modelagem de cenários de mudanças na região de Brasiléia aplicada ao Zoneamento Ecológico-Econômico do Estado do Acre. 88 


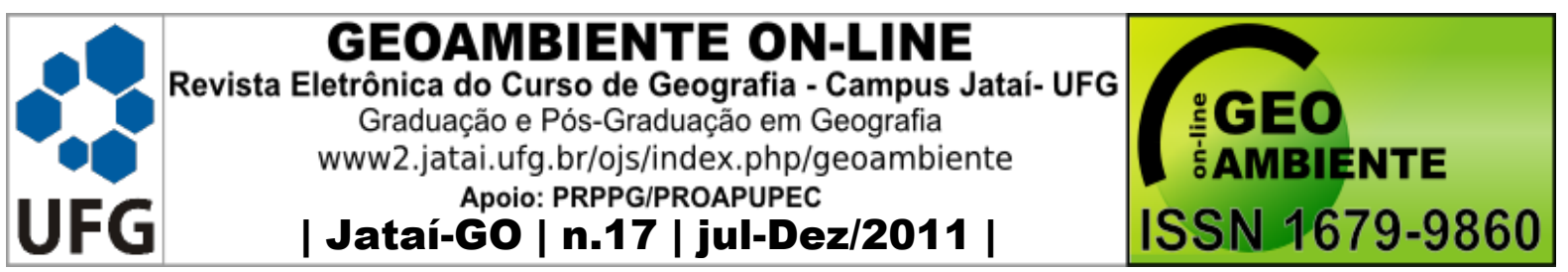

páginas. Dissertação de Mestrado. Programa de Pós-graduação em Geografia da Universidade Federal de Minas Gerais. Belo Horizonte, 2005. .

CASTRO, Iná Elias. O problema da escala. In: CASTRO, Iná Elias; GOMES, P.C.C.; CORRÊA, R.L. (Org.). Geografia: conceitos e temas. Rio de Janeiro: Bertrand Brasil, 2000.

CLAVAL, P. A Revolução Pós-Funcionalista e as concepções atuais da Geografia. In: MENDONÇA, F.; KOZEL, S. (Org.) Elementos de epistemologia da geografia contemporânea. Curitiba: Editora da Universidade Federal do Paraná, 2002. p.11-43.

CORRÊA, A. L. Espaço, um conceito chave da Geografia. In: CASTRO, I. E., GOMES, P.C.C., CORRÊA, R.L. (Org.). Geografia: conceitos e temas. Rio de Janeiro: Bertrand Brasil, 2000.

DIAS, L. C. Redes: emergência e organização. In: CASTRO, I. E. de et all.(Orgs). Geografia: Conceitos e temas. Rio de Janeiro: Bertrand Brasil, RJ. 1995.

DOLLFUS, Olivier. L'Espace Géographique. Trad. Oswaldo Bueno Amorim Filho. Paris: P.U.F., 1970.

EGLER, C. A. G. ; RIO, G. A. P. - Cenários para a Gestão Ambiental. In: SANTOS, Thereza Christina Carvalho; CÂMARA, João Batista Drummmond. (Orgs.). GEO Brasil 2002 Perspectivas do Meio Ambiente no Brasil. Brasília: Edições IBAMA, 2002, v., p. 295-316.

EMPRESA DE ASSISTÊNCIA TÉCNICA E EXTENSÃO RURAL DE MINAS GERAIS Emater-MG - Projeto Inovar: Sistema de Planejamento Participativo e Gestão Social volumes 1. - Minas Gerais, Secretaria de Agricultura, Pecuária e Abastecimento, 2004.

FABRÉ, N.N.; RIBEIRO, M. O. A Integridade Ecossistêmica no Zoneamento EcológicoEconômico da Biodiversidade. In: FABRÉ, N.N.; RIBEIRO, M. O Brasil. Caderno Temático: Biodiversidade no Âmbito do Zoneamento Ecológico-Econômico - Ministério do Meio Ambiente, Secretaria de Políticas para o Desenvolvimento Sustentável. Programa de Zoneamento Ecológico Econômico. 2007. p. 60-71. 


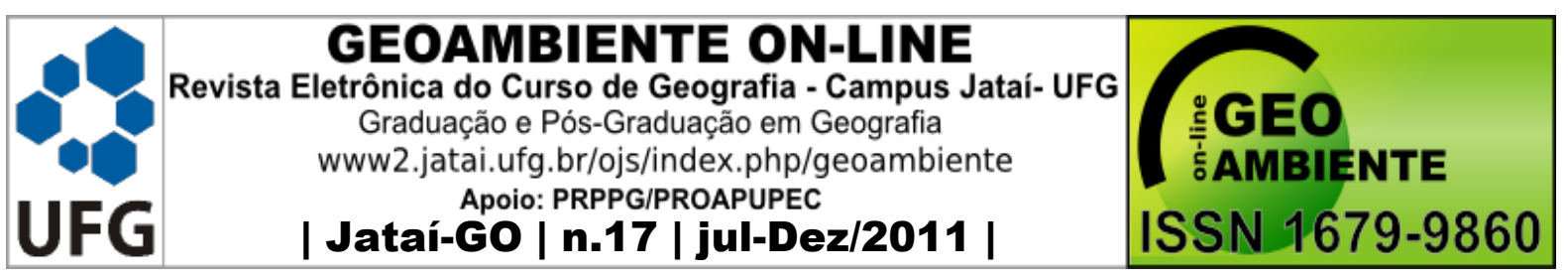

FIDALGO, E.C.C. Critérios para a Análise de Métodos e Indicadores Ambientais Usados na Etapa de Diagnóstico de Planejamentos Ambientais. 2003. 276 f. Tese (Doutorado) Universidade Estadual de Campinas, Faculdade de Engenharia Agrícola, Campinas, 2003.

FORTI, Maria Cristina. Ciclos Biogeoquímicos e Transferências de Espécies Químicas nas Interfaces de Ecossistemas Terrestres de Mata Atlântica: estudo de duas áreas contrastantes. INPE, São José dos Campos, 2003. 114P.

GINSBERG, Matt - Essentials of Artificial Inteligence -Morgan Kaufmann Publishers - USA, 1993.

HAESBAERT, R. "Desterritorialização: entre as redes e os aglomerados de exclusão.” , In: . CASTRO, I. E., GOMES, P.C.C., CORRÊA, R.L. (Orgs.) Geografia: conceitos e temas. p.165-205. Rio de Janeiro: Bertrand Brasil, 1995.

KOHLER, Heins Charles. A Escala de Análise Geomorfológica. Revista Brasileira de Geomorfologia, Ano 3, $N^{\circ}$ 1. 2002. p. 21-31.

MARQUES, J. M.; STERFATY-MARQUES, S. O papel da CPRM no ZEE da Amazônia. In: MARQUES, J. M.; STERFATY-MARQUES, S Brasil. Caderno Temático: Biodiversidade no Âmbito do Zoneamento Ecológico-Econômico - Ministério do Meio Ambiente, Secretaria de Políticas para o Desenvolvimento Sustentável. Programa de Zoneamento Ecológico Econômico. 2007. p. 72-82.

NITSH, Manfred. Planejamento sem rumo - Avaliação Crítica da Metodologia do Zoneamento Ecológico-Econômico nos Estados da Amazônia Brasileira. Berlim, 1998.

PIRES, J.S.R; PIRES, A.M.Z; MATTEO, K.C de. Abordagens para incorporação do tema biodiversidade no Zoneamento Ecológico-Econômico. In: PIRES, J.S.R; PIRES, A.M.Z; MATTEO, K.C de Brasil. Caderno Temático: Biodiversidade no Âmbito do Zoneamento Ecológico-Econômico - Ministério do Meio Ambiente, Secretaria de Políticas para o Desenvolvimento Sustentável. Programa de Zoneamento Ecológico Econômico. 2007b. p.2241.

PRUSKI, Fernando F.; RODRIGUEZ, Renata Del G.; NOVAES, Luciano F. de; SILVA , Demetrius D. DA; RAMOS, Márcio M.; TEIXEIRA, Alessandro DE F. Impacto das vazões 


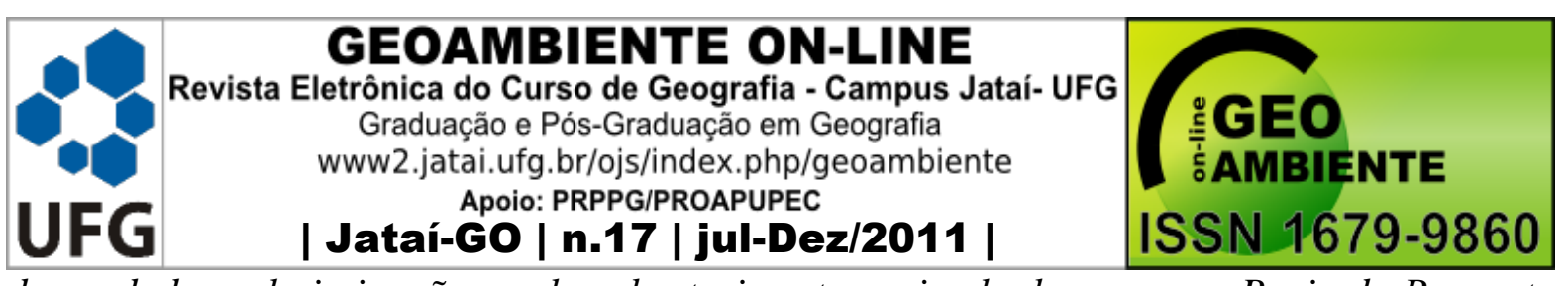

demandadas pela irrigação e pelos abastecimentos animal e humano, na Bacia do Paracatu.

Revista Brasileira de Engenharia Agrícola e Ambiental v.11, n.2, p.199-210, 2007

RODRIGUEZ, Renata Del G.; PRUSKI, Fernando F.; NOVAES, Luciano F. de; , RAMOS, Márcio M.; SILVA, Demetrius D. DA; TEIXEIRA, Alessandro DE F. Estimativa da Demanda de Água nas Áreas Irrigadas da Bacia do Rio Paracatu. Revista Engenharia Agrícola., Jaboticabal, v.27, n.1, p.172-179, jan./abr. 2007

SANTOS, Fabiana Borges Teixeira. A Construção Econômica Recente. In: Minas Gerais no Século XXI. Vol. 1. O Ponto de Partida. BDMG, Belo Horizonte: Rona Editora, 2002. p. 9-54.

SANTOS, Rozely Ferreira dos. Planejamento ambiental: teoria e prática. São Paulo, Ed. Oficina de Textos, 2004.

SEABRA, Manoel F. G. Geografia. Revista Orientação, São Paulo, n.5, p.9-17, out. 1984. 